\title{
The anti-scarring effect of corneal stromal stem cell therapy is mediated by transforming growth factor $\beta 3$
}

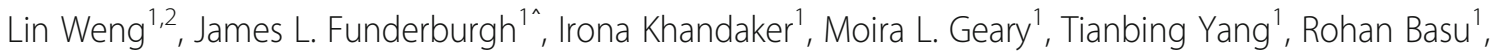
Martha L. Funderburgh ${ }^{1}$, Yiqin Du ${ }^{1}$ and Gary Hin-Fai Yam ${ }^{1^{*}}$ (D)

\begin{abstract}
Background: Corneal stromal stem cells (CSSC) reduce corneal inflammation, prevent fibrotic scarring, and regenerate transparent stromal tissue in injured corneas. These effects rely on factors produced by CSSC to block the fibrotic gene expression. This study investigated the mechanism of the scar-free regeneration effect.

Methods: Primary human CSSC (hCSSC) from donor corneal rims were cultivated to passage 3 and co-cultured with mouse macrophage RAW264.7 cells induced to M1 pro-inflammatory phenotype by treatment with interferonY and lipopolysaccharides, or to M2 anti-inflammatory phenotype by interleukin-4, in a Transwell system. The timecourse expression of human transforming growth factor $\beta 3$ (hTGF $\beta 3$ ) and hTGF $\beta 1$ were examined by immunofluorescence and APCR. TGF 33 knockdown for $>70 \%$ in hCSSC [hCSSC-TGF $33($ si)] was achieved by small interfering RNA transfection. Naïve CSSC and hCSSC-TGF 33 (si) were transplanted in a fibrin gel to mouse corneas, respectively, after wounding by stromal ablation. Corneal clarity and the expression of mouse inflammatory and fibrosis genes were examined.

Results: hTGF 33 was upregulated by hCSSC when co-cultured with RAW cells under M1 condition. Transplantation of hCSSC to wounded mouse corneas showed significant upregulation of hTGF $\beta 3$ at days 1 and 3 post-injury, along with the reduced expression of mouse inflammatory genes (CD80, C-X-C motif chemokine ligand 5, lipocalin 2, plasminogen activator urokinase receptor, pro-platelet basic protein, and secreted phosphoprotein 1). By day 14, hCSSC treatment significantly reduced the expression of fibrotic and scar tissue genes (fibronectin, hyaluronan synthase 2, Secreted protein acidic and cysteine rich, tenascin C, collagen $3 a 1$ and a-smooth muscle actin), and the injured corneas remained clear. However, hCSSC-TGF 33 (si) lost these anti-inflammatory and anti-scarring functions, and the wounded corneas showed intense scarring.
\end{abstract}

Conclusion: This study has demonstrated that the corneal regenerative effect of hCSSC is mediated by TGF 3 , inducing a scar-free tissue response.

Keywords: Cornea wound healing, Corneal stromal stem cells, TGF 33 , Inflammation, Fibrosis

\footnotetext{
*Correspondence: yamg@pitt.edu; gary.yam@gmail.com

James L. Funderburgh is deceased.

'Department of Ophthalmology, University of Pittsburgh School of medicine,

203 Lothrop Street, Pittsburgh, PA 15213, USA

Full list of author information is available at the end of the article
}

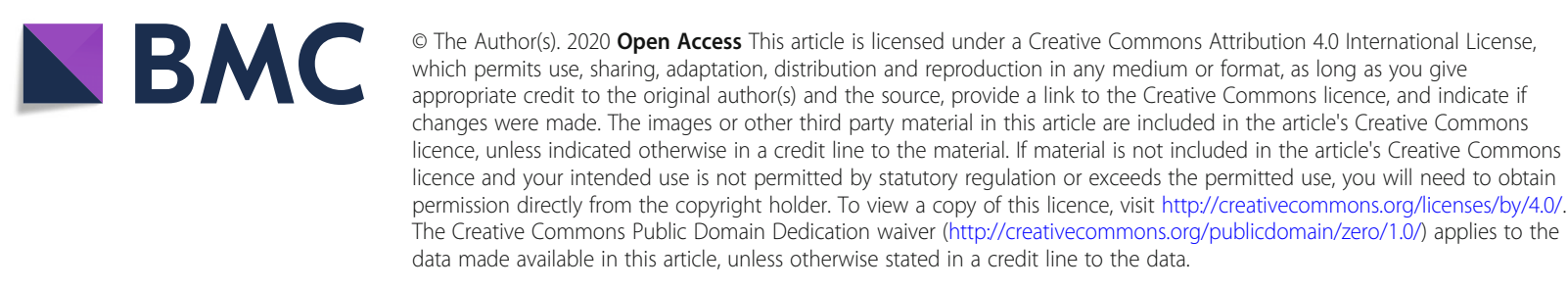




\section{Background}

Vision loss is a global burden. Corneal scarring due to trauma or infection is a major cause of blindness with about 10 million people being affected worldwide [1]. The conventional treatment for most existing corneal scars is corneal transplantation (penetrating or lamellar keratoplasty) [2]. Although this procedure is regarded as a highly developed and successful treatment, it is restricted by the global shortage of transplantable donor materials, allograft immune response, long-term graft survival and complications, and the need of surgical expertise [1]. There is a clear need for new approaches to prevent and treat corneal scarring. Corneal stromal stem cells (CSSC), identified in the anterior limbal stroma, represent the mesenchymal progenitors of stromal keratocytes, the dominant cell type inside the corneal stroma [3]. Under our optimized culture condition, primary human CSSC (hCSSC) at early passages exhibit stem cell features, including clonal growth and expression of stem cell markers (CD73, CD90, CD166, SSEA4, OCT4, ABCG2, Nestin and Pax6), as well as the ability to differentiate to keratocytes when induced by specific cytokines, and negligible expression of fibroblast-related genes, such as $\alpha$-smooth muscle actin ( $\alpha$ SMA) and tenascin C (TNC) [4-7]. Using different animal models, including lumican knockout mice and corneal stromal ablation, the applications of hCSSC prevented fibrotic tissue formation, reduced stromal haze, and restored the corneal stromal collagen fibril microstructure and corneal transparency [8-11]. The treated corneas regenerated organized collagenous extracellular matrix (ECM), similar to that in the native corneal stroma [12, 13]. These findings demonstrate the therapeutic potential of hCSSC in repairing stromal damages and regenerating the transparent cornea. The ex vivo propagation allows cells from one donor cornea to be used for multiple recipients or for multiple treatments, thus obviating the shortage of donor materials $[14,15]$.

The underlying mechanisms of how CSSC reduce corneal fibrosis and scarring, as well as regenerate stromal tissue, have yet to be elucidated. When cultured in low mitogen, ascorbate-containing media, hCSSC expressed an array of genes characteristic of keratocytes [3]. When cultured on a substratum of parallelly aligned nanofibers, the cells deposited layers of collagen fibrils packed in a highly organized pattern, closely resembling the native stromal lamellae $[15,16]$. After injection into mouse corneal stroma, the added cells remained viable for many months, and appeared as quiescent keratocytes, expressing typical genes of keratocytes and producing human ECM components [8, 9, 17]. These observations strongly indicate that CSSC differentiate by default into a keratocyte lineage and attain keratocyte functions. Moreover, injection of hCSSC into mouse corneal stroma did not elicit T-cell-mediated immune response, suggesting their ability to immune tolerance and block inflammatory signals $[8,11]$. The production of TSG-6 (tumor necrosis factor-stimulated gene 6) in wounded corneas further demonstrated the ability of hCSSC to block neutrophil infiltration, thus reducing the myofibroblast differentiation and scar-associated gene expression, including collagen 3a1 (Col3a1), tenascin $\mathrm{C}(\mathrm{TNC})$ and $\alpha$-smooth muscle actin ( $\alpha \mathrm{SMA})$ [18]. Recently, we have shown that $\mathrm{hCSSC}$ induced corneal regeneration via an indirect cellcell interaction, an effect consistent with the paracrine action of extracellular vesicles [19]. Such treatment effects disappeared when the vesicles were depleted of microRNAs, after specific Alix knockdown, suggesting that some microRNAs could have therapeutic effects on corneal fibrosis and stromal regeneration. Whether CSSC promote tissue regeneration by other mechanisms, in particular the scar-free healing response to produce transparent corneas, is under investigation.

Wound healing is regulated by various growth factors, including epidermal growth factor, fibroblast growth factor, platelet-derived growth factor, interleukins (e.g., IL-1, 2, 6, 8) and tumor necrosis factor- $\alpha$ (TNF $\alpha)$ [2022]. In different organs, including the cornea, members of transforming growth factor $\beta$ (TGF $\beta$ ) family are known as key regulators of fibrosis and scar formation; by way of mechanisms underlying the canonical TGF $\beta$ / Smad signaling [23-25]. Target inhibition and modulation of TGFß signaling using small interfering RNAs (siRNA) or neutralizing antibodies to regulate fibrosis and modulate wound healing have been reported in different studies [26-28]. The TGF $\beta$ family consists of three closely related isoforms ( $\beta 1, \beta 2$ and $\beta 3)$, with distinct roles in cell differentiation, tissue regeneration and embryonic development [29]. TGF $\beta 1$ and $\beta 2$ mediate tissue fibrosis and scar formation [30, 31], whereas TGF 33 acts as an inhibitor to these events [32]. The anti-fibrotic and scar-free healing effect of TGF $\beta 3$ have been reported in skin, lung and kidney models [33].

In this study, we examined TGF $\beta 3$ expression in hCSSC under pro- and anti-inflammatory conditions, mimicking different scenarios of tissue injury and wound healing process. The role of TGF $\beta 3$ and its knockdown expression on the stromal regenerative functions of hCSSC were also studied using a mouse corneal wound model.

\section{Material and methods}

\section{Human corneal biopsies}

Human corneal-scleral rims $(n=4)$, from de-identified donors younger than 60 years old and approved for research use, were obtained from the Center for Organ Recovery and Education, Pittsburgh, PA, USA. Tissues used were less than 9 days post-enucleation and 
preserved in Optisol GS (Bausch \& Lomb Inc., Rochester, NY, US). Research followed the tenets of the Declaration of Helsinki and was approved by the University of Pittsburgh Institutional Review Board (IRB) and Committee for Oversight of Research and Clinical Training Involving Decedents (CORID protocol \#161).

\section{Human corneal stromal stem cell isolation and culture}

Corneal rims, after the removal of corneal epithelium and endothelium, were dissected to isolate the anterior limbal stroma (1-2 $\mathrm{mm}$ wide, $0.5 \mathrm{~mm}$ deep), which was then cut into small segments for digestion $(16 \mathrm{~h}$ at $\left.37^{\circ} \mathrm{C}\right)$ with collagenase A $(0.5 \mathrm{mg} / \mathrm{ml}$, Sigma-Aldrich, St Louis, MO, US), as previously described [10]. The single cell suspension was passed through a cell strainer (70 $\mu \mathrm{m}$ pore size, Corning, NY, US) and cells were seeded on culture surface coated with FNC mix (AthenaES, Baltimore, MD, US) with stem cell growth medium (JM-H) containing $2 \%$ pooled human serum (Innovative Res, Novi, MI, US) [34]. At 70\% confluence, primary cells were collected after brief digestion with TrypLE Express (Thermo Fisher, Waltham, MA, US) and plated at 10 cells $/ \mathrm{cm}^{2}$ for clonal cell growth in subsequent passages. CSSC from a single donor cornea were expanded to P3 for use in experiments. Cultured cells expressed markers specific for mesenchymal stem cells (MSC) (including CD73, CD90 and CD166), and adult stem cells (including ABCG2, Nestin, Pax6, NGFR) by flow cytometry and RT-PCR $[7,10]$.

\section{TGF 33 knockdown in human CSSC by siRNA transfection}

Human CSSC were washed twice to remove dead cells and debris. In fresh culture medium, they were added with a mixture of Viromer Blue transfection reagent for Transfection of Adherent Cells (OriGene, Rockville, MD, US), Viromer Blue buffer and siRNA specific for hTGFß3 (42 nM; Ambion; antisense sequence: UCA GAG UGU ACA GUC CCA) or scrambled sequences (Silencer $^{\text {tm }}$ Select Negative Control \#2, Ambion), according to the manufacturer's protocol. After $24 \mathrm{~h}$, the cells were placed in a Transwell system and co-cultured with RAW at M1 induction (method in next section) for $44 \mathrm{~h}$. Total protein samples were collected for hTGF $\beta 3$ and hTGF $\beta 1$ expression by western blotting.

\section{In vitro inflammation assay}

In a Transwell system, mouse macrophage RAW264.7 cells (American Type Cell Collection, ATCC, Manassas, VA, US) were plated at $10^{4}$ cells $/ \mathrm{cm}^{2}$ in DMEM/F-12 (Thermo Fisher) with 10\% fetal bovine serum (FBS, Thermo Fisher) in the lower chamber. They were induced to M1 phenotype by treatment with interferon- $\gamma$ (IFN- $\gamma, 30 \mathrm{ng} / \mathrm{ml}$; BioLegend, San Diego, CA, US) and lipopolysaccharides (LPS, $100 \mathrm{ng} / \mathrm{ml}$; Sigma-Aldrich) or to M2 phenotype by interleukin-4 (IL-4, $20 \mathrm{ng} / \mathrm{ml}$; BioLegend). hCSSC were seeded at $2 \times 10^{4}$ cells $/ \mathrm{cm}^{2}$ in the upper chamber and cultured to near confluence before assembly with the lower chamber having RAW cells for co-culture. At regular intervals up to $72 \mathrm{~h}$, RAW cells were collected for the expression of M0, M1 and M2 phenotype markers, while hCSSC were assayed for hTGF $\beta 1$ and hTGF $\beta 3$ expression.

\section{Quantitative reverse transcription-polymerase chain reaction (qPCR)}

Cells were lysed in RLT reagent (Qiagen, Germantown, MD, US) and total RNA was extracted using RNeasy Miniprep (Qiagen) followed by RNase-free DNase digestion (New England Biolabs, Ipswich, MA, US) according to the manufacturer's instructions. RNA was precipitated by ethanol and quantified using NanoDrop One (Thermo Fisher). After reverse transcription using SuperScript III RT-PCR kit (Thermo Fisher) and random hexanucleotide primers, cDNA was assayed for candidate gene expression with specific TaqMan probes using universal master mix (Thermo Fisher) or specific target primers (Table 1) using SYBR Green Real-Time Master Mix (Life Technologies, Carlsbad, CA, US) in a StepOnePlus Real-Time PCR System (Applied Biosystems, Foster City, CA, US). Experiments were run in triplicates. The relative RNA abundance was assayed after normalization with housekeeping $18 \mathrm{~S}$ or glyceraldehyde 3-phosphate dehydrogenase (GAPD $\mathrm{H})$ genes and compared to M0 condition. The fold changes of each gene were calculated by $2^{-\Delta \Delta C T}$ and expressed as mean \pm standard deviation (SD).

\section{Western blotting}

Cells were lysed in a radioimmunoprecipitation assay (RIPA) buffer (Thermo Fisher) added with Complete ${ }^{\mathrm{Tn}}$ protease inhibitor cocktail (Roche, Indianapolis, IN, US) and phenylmethylsulfonylfluoride (PMSF, $1 \mathrm{mM}$, SigmaAldrich). Soluble proteins were denatured in sodium dodecylsulfate (SDS, 2\%, Sigma-Aldrich) and $\beta$ mercaptoethanol (1\%, Sigma-Aldrich), resolved by 4 to 20\% SDS-polyacrylamide gel electrophoresis (SDS-PAGE, BioRad, Hercules, CA) and transferred to PVDF-FL membrane (BioRad). After blocking with 5\% non-fat milk, the membrane was incubated with antibodies against TGF 33 (Abcam), TGF 1 1 (Abcam) and housekeeping $\alpha$-tubulin (Sigma-Aldrich), followed by species-specific secondary IRDye-labeled antibodies (LI-COR Biosciences, Lincoln, NE, US). Staining signals were detected and digitized using Odyssey scanner (LI-COR). The specific band density of TGF $\beta 3$ was measured and normalized to that of $\alpha$-tubulin for relative expression in each sample. Experiments were conducted in duplicates. 
Table 1 Expression primers

\begin{tabular}{|c|c|c|c|}
\hline & Gene & GeneBank Accession No. & Sequences \\
\hline \multicolumn{4}{|c|}{ Oligonucleotide primers } \\
\hline \multirow[t]{2}{*}{1} & hTGF $\beta 1$ & NM_000660.7 & F: GACTGCGGATCTCTGTGTCATT \\
\hline & & & R: CAGTAGTGTTCCCCACTGGTC \\
\hline \multirow[t]{2}{*}{2} & hTGFß3 & NM_003239.4 & F: CTTCCAGATCCTTCGGCCAG \\
\hline & & & R: ATCAAAGGACAGCCACTCGG \\
\hline \multirow[t]{2}{*}{3} & hTSG6 & NM_007115.4 & F: AAGGATGGGGATTCAAGGAT \\
\hline & & & R: GCTTGTATTTGCCAGACCGT \\
\hline \multirow[t]{2}{*}{4} & mARG1 & NM_031508.1 & F: GATTATCGGAGCGCCTTTCT \\
\hline & & & R: CCACACTGACTCTTCCATTCTT \\
\hline \multirow[t]{2}{*}{5} & mCol3a1 & NM_009930.2 & F: CGTAAGCACTGGTGGACAGA \\
\hline & & & R: CGGCTGGAAAGAAGTCTGAG \\
\hline \multirow[t]{2}{*}{6} & mFN1 & NM010233.2 & F: TACTCGAGCCCTGAGGATGG \\
\hline & & & R: GCAAGGCAACCACACTGACT \\
\hline \multirow[t]{2}{*}{7} & mHAS2 & BC080281 & F: CCAAGGTTCTGCTTCCTCAC \\
\hline & & & R: CTCTCCATACGGGGAGAGTC \\
\hline \multirow[t]{2}{*}{8} & miNOS & NM_001313922.1 & F: TCACCTTCGAGGGCAGCCGA \\
\hline & & & R: TCCGTGGCAAAGCGAGCCAG \\
\hline \multirow[t]{2}{*}{9} & mSPARC & XM_030245730.1 & F: ATGAGGGCCTGGATCTTCTT \\
\hline & & & R: CACGGTTTCCTCCTCCACTA \\
\hline \multirow[t]{2}{*}{10} & mSMA & NM_009696.3 & F: TGTGCTGGACTCTGGAGATG \\
\hline & & & R: GAAGGAATAGCCACGCTCAG \\
\hline \multirow[t]{2}{*}{11} & mTNC & NM_035737.2 & F: GACTGCCCTGGGAACTGTAA \\
\hline & & & R: CATAGCCTTCGAAGCACACA \\
\hline \multicolumn{4}{|c|}{ TaqMan assay IDs } \\
\hline 7 & hTGFß1 & NM_000660.7 & Hs99999918_m1 \\
\hline 8 & hTGF $\beta 3$ & NM_003239.4 & Hs04398989_m1 \\
\hline 9 & hGAPDH & NM_001256799.3 & Hs01120607_g1 \\
\hline 10 & mCD80 & NM_009855.2 & Mm00711660_m1 \\
\hline 11 & mLcn2 & NM_032517.1 & Mm01324470_m1 \\
\hline 12 & mPLAU & NM_032899.1 & Mm01149438_m1 \\
\hline 13 & mPpbp & NM_023785.3 & Mm00470163_m1 \\
\hline 14 & mSpp1 & NM_001204203 & Mm00436767_m1 \\
\hline 15 & mG6pdx & NM_032034.3 & Mm00656735_g1 \\
\hline
\end{tabular}

$h=$ human; $m=$ mouse

\section{Immunocytochemistry}

Cells cultured on sterile glass coverslips were fixed in $2 \%$ neutral-buffered paraformaldehyde (EM Sciences, Hatfield, MA, US) for $20 \mathrm{~min}$ at room temperature. The rinsed samples were permeabilized and blocked in buffer containing 3\% normal goat serum (Thermo Fisher) and $0.3 \%$ Triton X-100 ( $\mathrm{Tx}$, Sigma-Aldrich) for $45 \mathrm{~min}$, followed by incubation with rabbit polyclonal antibody against human TGF 33 (Abcam) or host species-matched isotype-specific immunoglobulin (Ig) overnight at $4{ }^{\circ} \mathrm{C}$.
After washes using PBS with 0.1\% BSA and 0.1\% Tween20, the samples were stained with anti-rabbit Ig conjugated with AlexaFluor 488 (Thermo Fisher) and anti-human nuclear antigen-PE (phycoerythrin) conjugate (Abcam) for an hour at room temperature in the dark. After washing, the coverslips were mounted with Fluoromount-G ${ }^{\oplus}$ containing 4'6-diamidino-2-phenylindole (DAPI) (Thermo Fisher) and viewed under confocal microscopy (FluoView 1000, Olympus). Experiments were performed in triplicates. 


\section{Murine corneal stromal wound model and CSSC treatment}

The animal experiments were conducted in strict accordance with the Guidelines for the Care and Use of Laboratory Animals of the National Institutes of Health (NIH, Bethesda, MD, US) and The Association for Research in Vision and Ophthalmology statement for the use of animals in ophthalmic and vision research. The protocol was approved by the Institutional Animal Care and Use Committee of The University of Pittsburgh (ISO00012511). C57/BL6 mice $(n=20$ per experiment, total $n=60$ for triplicate runs) Charles River Lab, Wilmington, MA, US), 7-8 weeks of age, were housed in an AALAC-approved ABSL2 facility, and provided an unrestricted standard diet. They were anesthetized by intraperitoneal ketamine $(50 \mathrm{mg} / \mathrm{kg})$ and xylazine $(5 \mathrm{mg} /$ $\mathrm{kg}$ ), and both eyes received topical proparacaine hydrochloride (0.5\%, Alcaine ${ }^{\ominus}$ Alcon, Fort Worth, TX, US). After saline rinses, the central corneal epithelium $(2 \mathrm{~mm}$ diameter) was debrided using Algerbrush II (Accutome Inc., Malvern, PA, US) and surgical blade \#15. The basement membrane and anterior stromal tissue was further removed by a second application of AlgerBrush [17]. The eyes were rinsed and briefly dried before cell treatment. Immediately after wounding, hCSSC in $10^{4}$ cells/ $\mu \mathrm{l}$ human fibrinogen $(70 \mu \mathrm{g} / \mathrm{ml}$, Sigma-Aldrich) were mixed with $0.5 \mu \mathrm{l}$ thrombin $(100 \mathrm{U} / \mathrm{ml}$; Sigma-Aldrich) and applied to the wound site. After gelation, a second round of fibrinogen and thrombin was applied to the gel surface. The eyes received topical gentamicin $(0.3 \%$, Genoptic $^{\oplus}$, USP, Rockville, MD, US) and ketoprofen (3 $\mathrm{mg} / \mathrm{kg}$ ) for analgesia. We carefully designed the grouping of mouse eyes for injury and cell treatment so that each mouse had one functional eye for daily use and survival. In each set of experiment, 10 mice had one cornea injured, which served as sham control treated with medium without cells; and the other cornea remained normal. Another 10 mice had both corneas injured with one of them treated with hCSSC (reported to retain vision) $[9,10]$, and the other with hCSSC-TGF 33 (si). Experiments were done in triplicates.

\section{Corneal scar intensity measurement}

At day 14 post-wounding and cell treatment, the eyes were scanned with a Spectral domain Optical Coherent Topography (SDOCT) (Bioptigen, Durham, CA, US). Scanned images were analyzed in a masked fashion regarding the treatments. Image processing and analysis were conducted using Image $(\mathrm{NIH})$ and MetaMorph 7.7.3 (Molecular Devices Inc., San Jose, CA, US) [10]. For scar intensity quantification, pixel intensity were obtained from the corneal region with Image and the average background intensity was subtracted. Control eyes were used to set the lower threshold and scar intensity of each mouse and the overall mean and SD are displayed graphically.

\section{Mouse corneal tissue collection for RNA expression analysis}

At post-wounding and treatment days 1, 3 and 14, mice were sacrificed. After enucleation, corneas were immediately excised on ice. Four to six corneas per group were pooled in ice-cold RLT lysis buffer (Qiagen) and disrupted with a MagNA Lyser Green Beads kit (Roche) at $6000 \mathrm{rpm}$ for $50 \mathrm{~s}$, in a MagNA Lyser Instrument (Roche), ford 6 cycles, each with intermittent cooling. The lysate was passed through QIAshredder column and total RNA was isolated using RNeasy Miniprep (Qiagen) following manufacturer's instructions. Total RNA $(0.5 \mu \mathrm{g})$ was transcribed to cDNA by SuperScript III (Thermo Fisher). Gene expression was assayed by qPCR with specific primers or TaqMan probes as listed in Table 1. Experiment was done in triplicates.

\section{Statistical analysis}

All data were presented as mean \pm SD. Mean value was compared by two-tailed $t$ tests or ANOVA with a post hoc Bonferroni test using GraphPad Prism 7. Corneal scar intensities were compared using non-parametric Mann-Whitney $U$ test. $P<0.05$ was considered statistically significant.

\section{Results}

Human CSSC expressed TGF $\beta 3$ in M1 pro-inflammatory phase of mouse macrophages

The functional response and stability of mouse RAW264.7 macrophages (RAW) was examined by cytokine stimulation to M1 (pro-inflammatory) and M2 (anti-inflammatory) conditions. RAW propagated at M0 phase (Fig. 1a) were treated with LPS and IFNY to M1 phenotype and showed a consistent upregulation of mouse iNOS (inducible nitric oxide synthase) at various time intervals (Fig. 1b). The M1 macrophages were differentiated, appeared spindle-shape and adhered to the culture surface (Fig. 1a). When treated with IL4, RAW were maintained as small, rounded morphology and had upregulated mouse ARG1 (arginase 1) expression (Fig. $1 \mathrm{a}$ and $\mathrm{b})$, indicative of the M2 phenotype. Similar expression patterns were reported in different studies [35, 36]. The co-culture of hCSSC with RAW at the M1 stage demonstrated an inflammation-associated cellular response with an elevated expression of TSG-6 (Fig. 1b). In this pro-inflammatory condition, hTGF 33 was significantly upregulated (Fig. 1c), starting at $24 \mathrm{~h}$ of coculture and continuing to increase until the end of experiment $(84 \mathrm{~h})$. This induction was absent in M0 and M2 phases of macrophages. On the other hand, there 


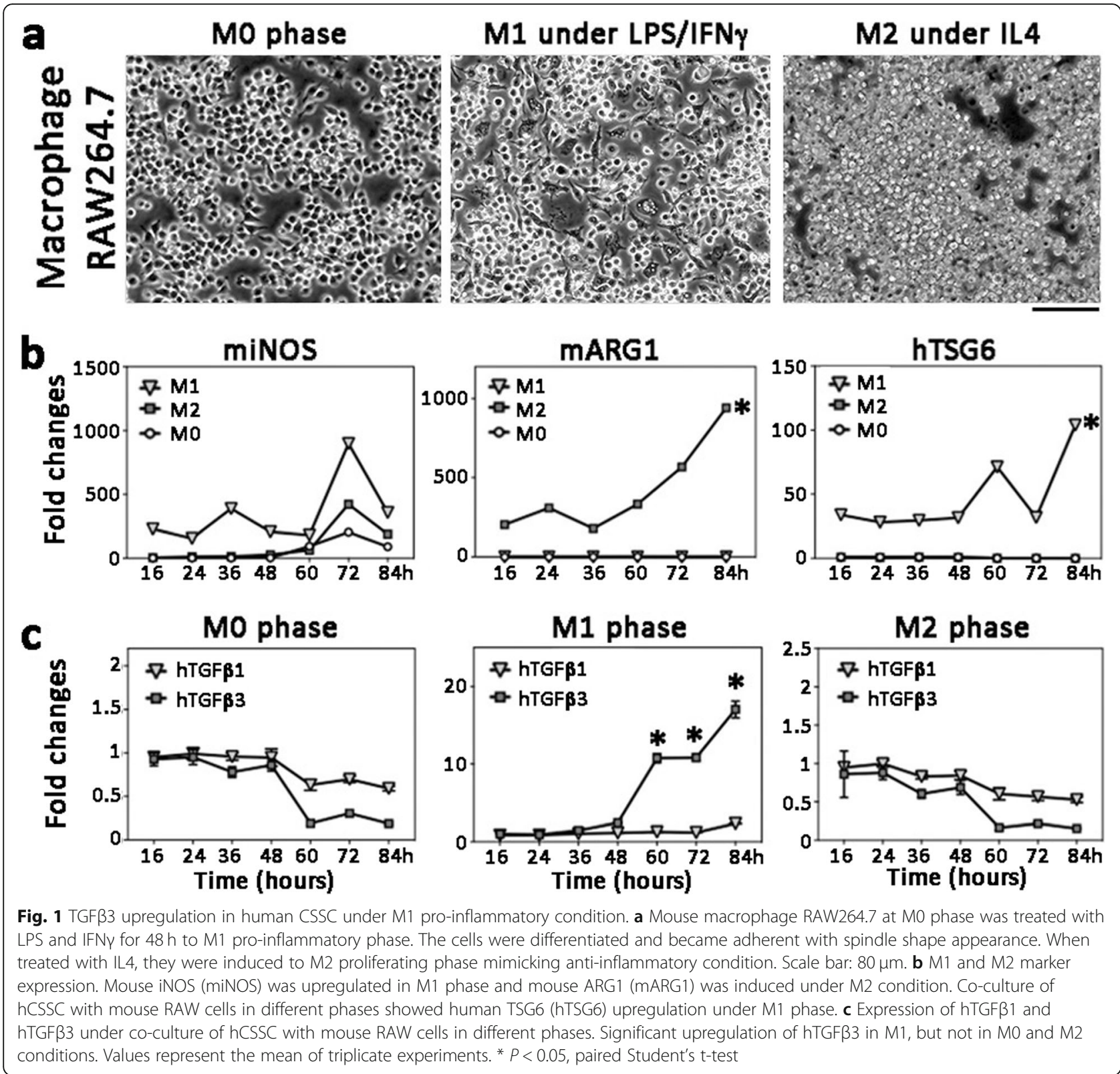

was no significant changes of hTGF $\beta 1$ expression in hCSSC under M0, M1, or M2 conditions.

Immunostaining showed that TGF 33 was expressed in hCSSC when co-cultured with RAW cells in M1 phase (Fig. 2a). Since the anti-TGF 33 antibody appeared labeled in mouse RAW cells (both nuclear and cytoplasmic) (Fig. 2d), the specificity in hCSSC was distinguished by the co-labelling of $\mathrm{HuNu}$ (human specific nuclear antigen). In HuNu-labelled hCSSC, TGF 33 expression was evident under the M1 proinflammatory condition. TGF 33 signals in hCSSC were located inside the cytoplasm as a diffuse punctate pattern with some labelling close to the plasma membrane (Fig. 2a). When co-cultured with RAW cells at M2 and M0 phases, hCSSC negligibly expressed TGF $\beta 3$ (Fig. 2b and c).

M1 macrophages induced hCSSC to produce TGF $\beta 3$ via non-contact cell-to-cell communication

In a Transwell system, hCSSC and RAW cells were placed in separate chambers. In the presence of RAW cells treated with LPS + IFNY to induce M1 pro-inflammatory condition, the expression of hTGF 33 in hCSSC was detected after 24 $\mathrm{h}$ and was significantly upregulated by $8.2 \pm 0.1$ folds at 48 h, compared to the untreated control (Fig. 3a). Without RAW co-culture, hCSSC under M1 induction did not show any hTGF 33 changes. When comparing this Transwell coculture of hCSSC with RAW cells under M0, M1 or M2 


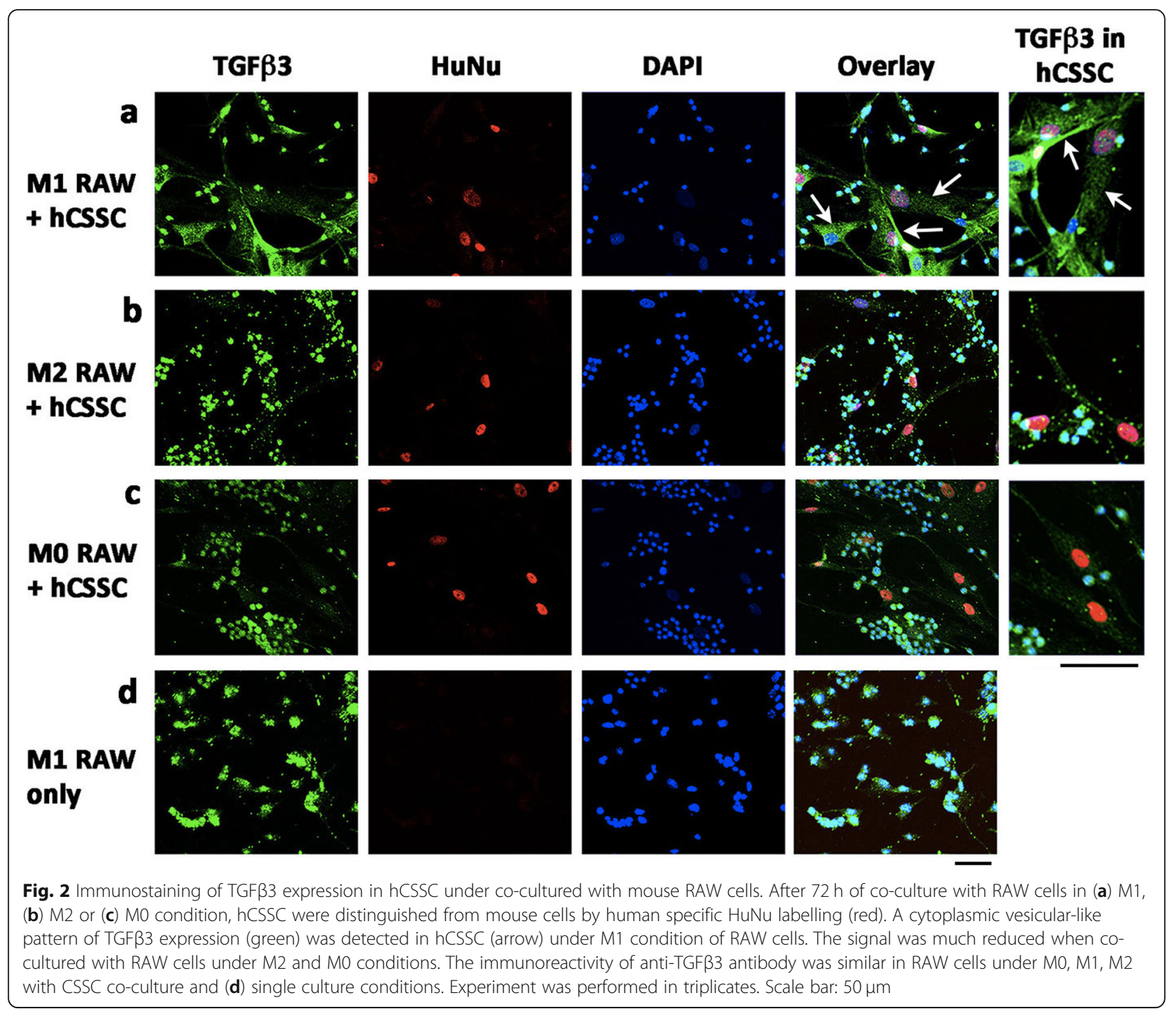

conditions for $36 \mathrm{~h}$, we observed a significant upregulation of hTGF 33 in hCSSC in the presence of M1 RAW cells, but not with M0 and M2 cells (Fig. 3b). Again, TGF $\beta 1$ expression was not altered under different phases (Fig. 3b).

\section{Suppression of hTGF $\beta 3$ expression in hCSSC under M1} condition by siRNA

In the Transwell setting, (i) naïve hCSSC, (ii) hCSSC transfected with hTGF 33 siRNA [hCSSC- TGF $33(\mathrm{si})$ ], or (iii) hCSSC transfected with scrambled sequences were co-cultured with RAW cells under M1 condition. After $48 \mathrm{~h}$, hCSSC-TGF $33(\mathrm{si})$ showed reduced hTGF 33 expression, by $70-84 \%$ of that in naïve hCSSC (Fig. 4a). This was not found for hCSSC transfected with scrambled sequences. The expression of hTGF $\beta 1$ was not affected by hTGF $\beta 3$ knockdown (Fig. 4b).
hTGF $\beta 3$ was upregulated in mouse stromal wounds after hCSSC treatment

Our in vitro models showed hTGF 33 upregulation in hCSSC under a pro-inflammatory condition. We further explored this association with an in vivo model of corneal injury and wound healing. Human CSSC were applied in a fibrin gel to mouse corneal stromal ablation wounds. At day 1 and 3 after wounding and cell treatment, hTGF $\beta 3$ was significantly upregulated, when compared to hCSSC before transplantation $(P<0.05$, One-way ANOVA) (Fig. 5). The expression of hTGF 33 on day 1 was increased by $63 \pm 8$ folds (Fig. 5a) and to a high of $256 \pm 63$ folds at day 3 (Fig. 5b). This change was negligible with hCSSCTGF 33 (si) treatment. In contrast, the expression of hTGF $\beta 1$ had no change on day 1 post-wounding and treatment (Fig. 5a) and had only mild elevation at day 3 ( $4 \pm 1.8$ folds, compared to non-transplanted hCSSC; Fig. $5 b)$. In terms of hTGF $\beta 3 / \beta 1$ ratio, hCSSC treatment for 1 

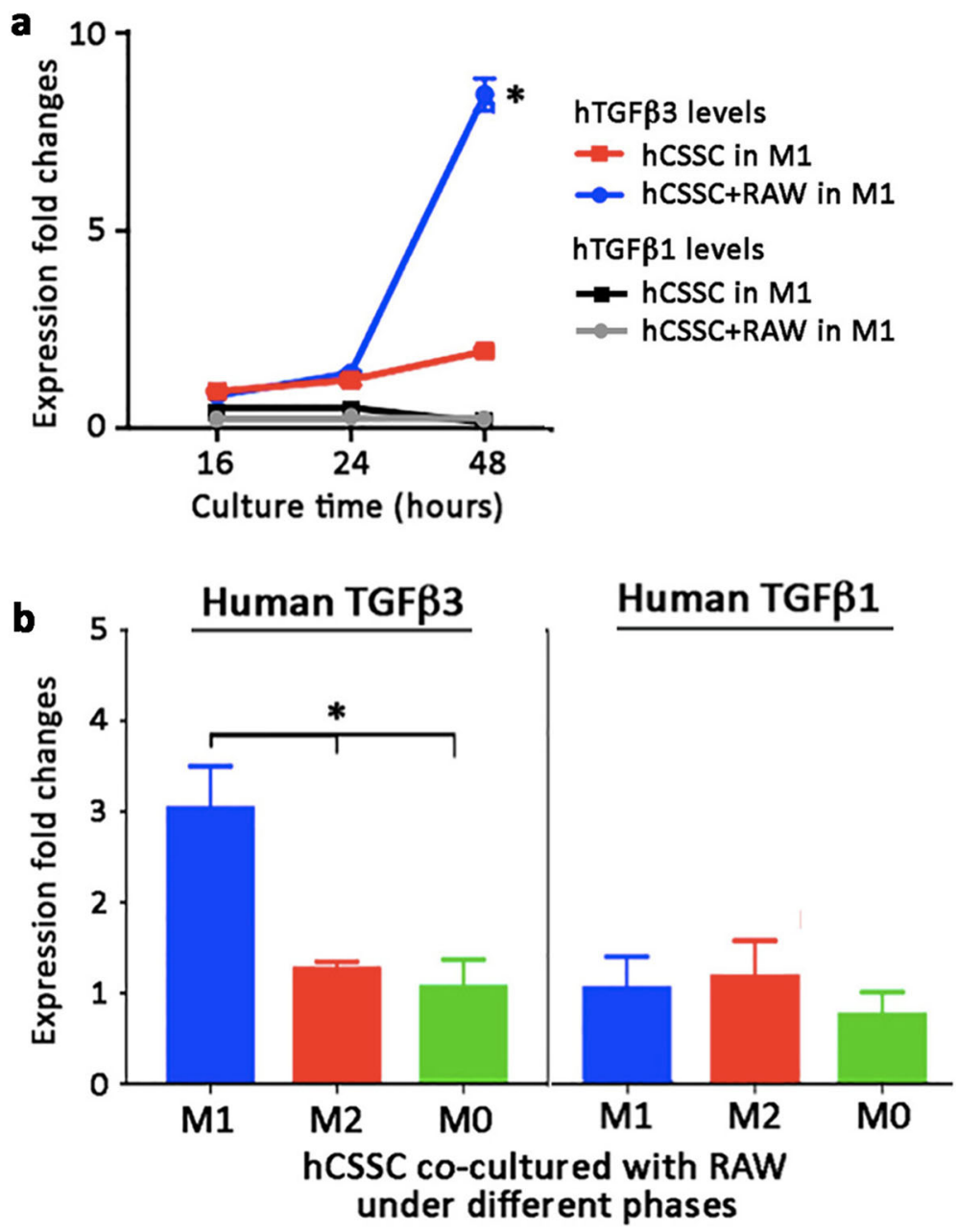

Fig. 3 M1-type macrophages induced TGF 33 expression in hCSSC via paracrine action. a In a Transwell system, the co-culture of hCSSC and mRAW cells at M1 condition in separate chambers for $48 \mathrm{~h}$ showed a significant hTGF 33 upregulation from hCSSC. The induction was detectable after $24 \mathrm{~h}$. For hCSSC alone under M1 induction, there were no clear changes of hTGF $\beta 3$ expression. The expression of hTGF $\beta 1$ was not altered in hCSSC alone or in co-culture with mRAW cells after M1 induction. b hTGF 33 upregulation was significantly greater when hCSSC were co-cultured with mRAW cells under M1 but not under M2 and M0 conditions. hTGF $\beta 1$ expression remained unchanged under different conditions. Mean and SD are calculated from triplicate experiments. ${ }^{*} P<0.05$, paired Student's t-test

and 3 days showed similar range of values (Fig. 5a and b). The mean ratio at day 1 was 45 and on day 3 was 65 ( $n=$ 5 mice per group with injury only and injury with hCSSC treatment, respectively).

Both anti-inflammatory and anti-fibrotic effects of hCSSC treatment on mouse corneal stromal wounds were reduced by TGF $\beta 3$ knockdown

In our previous analysis using nanoString ${ }^{\mathrm{Tm}}$ for Mouse Inflammation and Mouse Pan-Cancer Panels, a number of mouse inflammatory genes were affected by hCSSC treatment [19]. We assayed the RNA expression of early inflammatory genes, including $C D 80, C-X-C$ motif chemokine ligand 5 (CXCL5), lipocalin 2 (Lcn2), plasminogen activator urokinase receptor (PLAUR), pro-platelet basic protein (Ppbp) and secreted phosphoprotein 1 $(S p p 1)$. These genes were upregulated at day 1 after wounding when compared to normal corneas, and the elevated expression was significantly suppressed by hCSSC treatment (Fig. 6). This anti-inflammatory effect was abolished by the treatment with hCSSC-TGF 33 (si) $(P<0.05$, one-way ANOVA), with levels of gene expression similar to that of the wounded corneas without treatment.

At day 14 post-wounding and cell treatment, the scarreducing effect by hCSSC was abolished when the treatment used hCSSC-TGF 33 (si) (Fig. 7a). On brightfield illumination of the corneas, the mean scar intensity ( $n=6$ corneas per group) was significantly greater after treatment with hCSSC-TGF $33(\mathrm{si})$ when compared to 


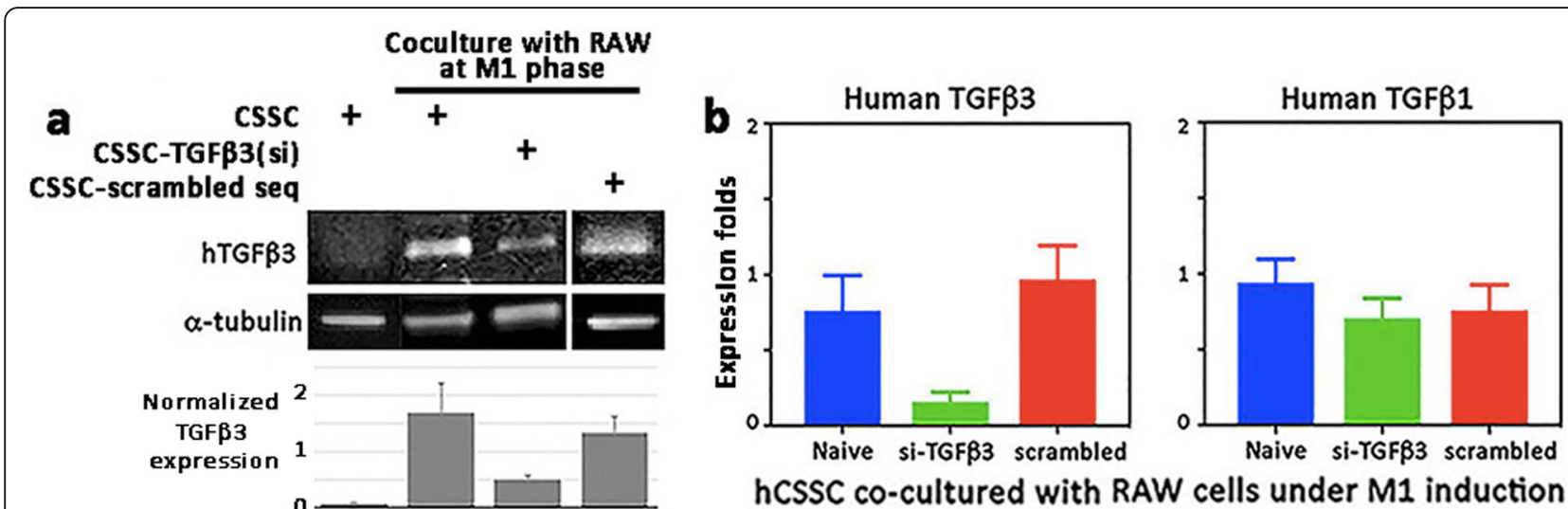

Fig. 4 TGF $\beta 3$ knockdown in human CSSC. a Human CSSC were transfected with hTGF $\beta 3$ siRNA or scrambled sequences. After co-culture with RAW cells under M1 phase in a Transwell system for $48 \mathrm{~h}$, naïve hCSSC and hCSSC transfected with scrambled sequences showed similar TGF 33 upregulation, whereas cells with TGF $\beta 3$ siRNA transfection showed reduced expression (decreased by 70-84\%) of hTGF 33 . Similar results were obtained in two separate experiments. $\mathbf{b}$ The reduced hTGF $\beta 3$ expression was specific for si-TGF $\beta 3$ transfection, while there was no changes for scrambled sequences. The expression of hTGF $\beta 1$ remained unchanged with TGF $\beta 3$ knockdown in CSSC. Mean and SD are calculated from triplicate experiments

naïve hCSSC $(P=0.008$, Mann-Whitney U test; Fig. 7b). Expression of mouse fibrosis genes (Col3a1 and $\alpha S M A$ ) was significantly suppressed by naïve hCSSC treatment $(P<0.05$, paired Student's t-test) but remained elevated with hCSSC-TGF 33 (si) (Fig. 7c). This was similarly observed for other fibrotic genes, including fibronectin (FN1), hyaluronan synthase 2 (HAS2), Secreted protein acidic and cysteine rich (SPARC) and tenascin C (TNC) (Fig. 7d).

\section{Discussion}

In this study, we describe a novel underlying mechanism of hCSSC regeneration of corneal stroma after corneal injury. Specifically, our data demonstrate that: (i) TGF $\beta 3$ expression by hCSSC is upregulated in an inflammatory milieu in vitro; (ii) hTGF 33 is expressed after hCSSC treatment to the stromal wound of mouse corneas and (iii) the specific knockdown of TGF $\beta 3$ attenuates these anti-inflammatory and anti-fibrotic activities of hCSSC in vivo. These findings have deepened our understanding on the therapeutic regulation of CSSC to suppress corneal haze and scarring, and to regenerate stromal tissue.

TGF $\beta 3$ was expressed by hCSSC in an inflammatory milieu in vitro and in vivo. We set up a co-culture system of hCSSC interacting with murine macrophages (RAW264.7 cells) having M0, M1 and M2 phenotypes, mimicking the uncommitted, pro-inflammatory and anti-inflammatory scenarios, respectively, during injury and wound healing process. Human TGF 33 was significantly upregulated in hCSSC in the presence of M1-type macrophage (pro-inflammatory). The induction was detected at around $24 \mathrm{~h}$ of co-culture and escalated thereafter. Similar results were detected when hCSSC were co-cultured with M1 macrophage in a Transwell system, suggesting paracrine action of diffusible molecules from the activated macrophages. Since negligible TGF $\beta 3$ changes were detected when hCSSC alone was treated with IFN $\gamma$ and LPS, the cytokine induction is suggested to be specifically associated to the presence of M1 macrophages, and possibly the secreted molecules from macrophages. The production of IL- $1 \beta$ and IL- 6 from activated macrophages has been shown to upregulate TGF 33 expression in chondrocytes $[37,38]$. Here, we show that CSSC might adopt a similar response to the activated macrophages. Further studies will identify the molecular mechanisms underlying CSSC responses in this wound-associated pro-inflammatory condition.

Using an in vivo mouse corneal wounding model, hTGF 33 expression was also significantly upregulated after hCSSC treatment; there was an increase from day 1 to 3 post-treatment (the mean change of 63 folds at day 1 increased to 256 folds at day 3). At a later time point (day 14), the treated corneas were devoid of haze formation and remained clear, similar to our previous studies $[9,18]$. This therapeutic effect was suspended with hCSSC treated to TGF $\beta 3$ knockdown. As such, the antiinflammatory and anti-fibrotic functions were lost, and the injured corneas developed intense scarring. The timing of TGF $\beta 3$ production by hCSSC in the early wound healing phase was similar to that of TSG-6 expression, which was also detectable after 1 day of hCSSC treatment on fresh stromal wounds [18]. Corneal injuryinduced inflammation is initiated with the infiltration of neutrophils, followed by macrophages. CSSC, displaying the characteristics of MSC, could serve as a guardian against the excessive inflammatory responses through multiple mechanisms e.g., the expression of IL-1 receptor antagonist blocking IL-1 inflammatory signaling, 

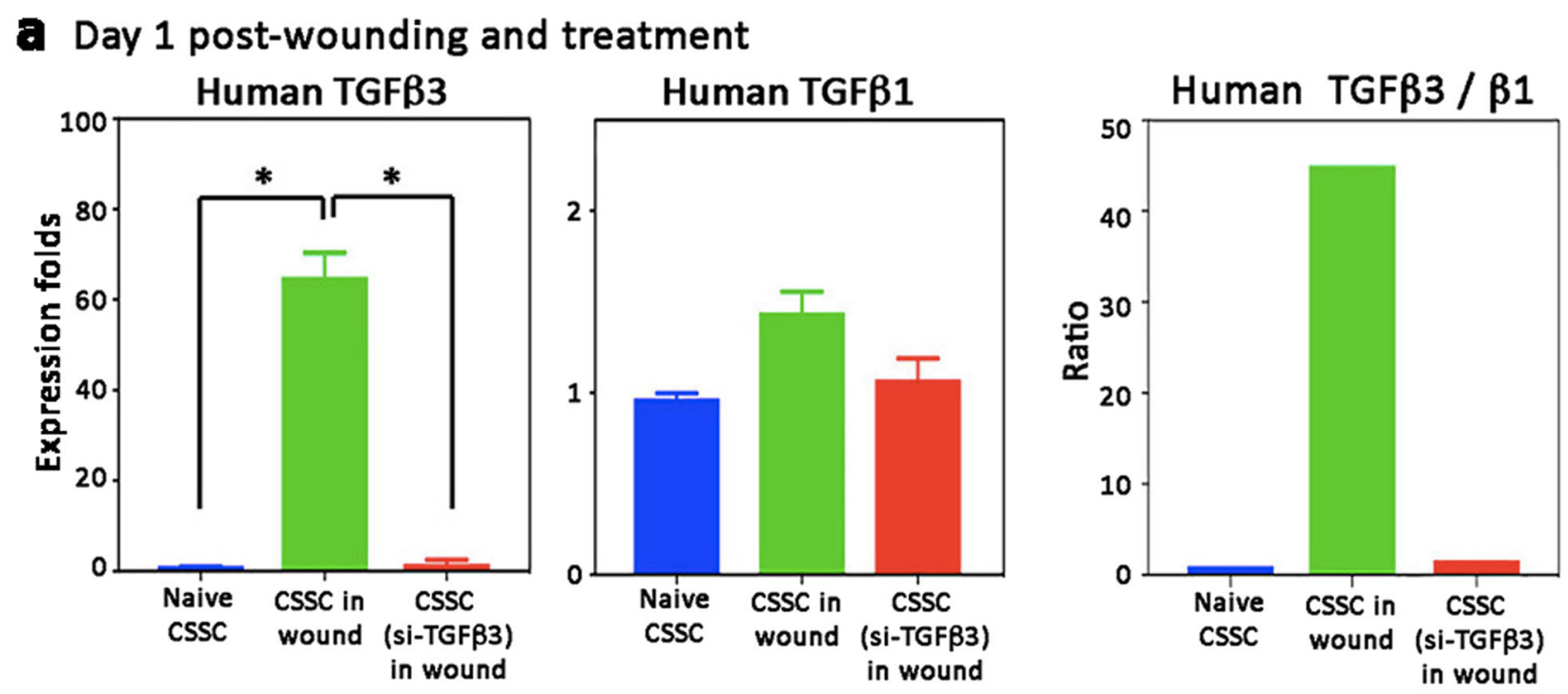

\section{b Day 3 post-wounding and treatment}
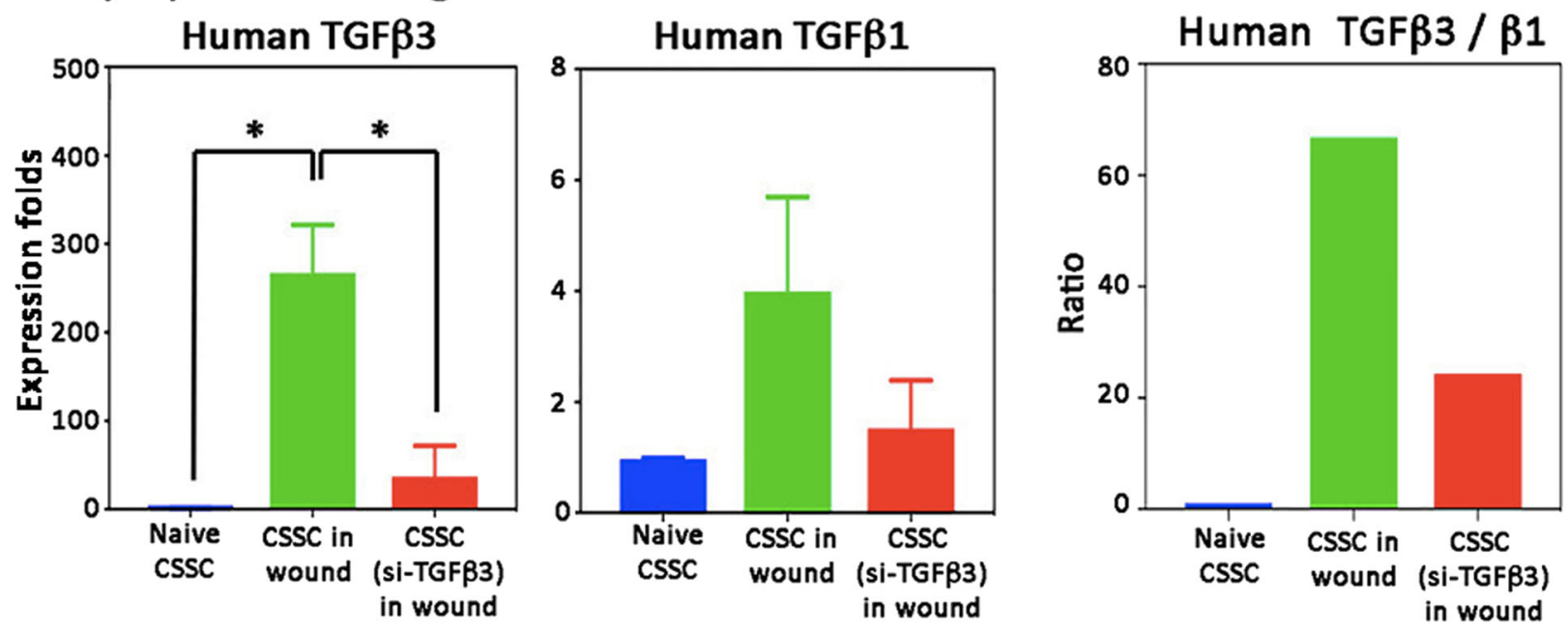

Fig. 5 TGF 33 was upregulated after hCSSC treatment to injured mouse corneas. After stromal ablation wounding, hCSSC or hCSSC-TGF $33($ (Si), suspended in fibrin gel, were applied to the fresh wounds. At 2 different time points, a 1 day and $\mathbf{b} 3$ days, the expression of hTGF $\beta 3$ was significantly induced in corneas treated with hCSSC but not with hCSSC-TGF $\beta 3$ (si). On the other hand, the expression of hTGF $\beta 1$ was not altered at either time points. The ratio of hTGF $\beta 3 / \beta 1$ was maintained between day 1 and day 3 post-treatment. Mean and SD represent data from triplicate experiments. ${ }^{*} P<0.05$, paired Student's t-test

TSG-6 production to reduce NF- $\mathrm{kB}$ signaling in the resident macrophages while producing prostaglandin E2 to induce IL-10 expression by macrophages, as well as the expression of sodium dismutase 3 to reduce radical oxygen species in suppressing innate immunity [39]. Among them, the blocking of neutrophil infiltration is crucial at the early wound stage to control inflammation; however, this action might not be effective for anti-fibrosis as hCSSC producing TSG-6 still exhibited fibrotic gene expression [18]. Though our work has demonstrated that CSSC functions through TGF $\beta 3$ signaling to control fibrosis development, whether any coordinated or synergistic action by TGF $\beta 3$ and TSG- 6 in controlling inflammation and wound healing awaits further investigation. In the present corneal wounding study, only female mice were used due to them being less aggressive after wounding and during social housing, to give reliable results. In fact, both sexes have been shown to exhibit similar responses of corneal stromal wound healing, scar formation and stem cell treatment outcomes in our continuous studies (manuscript submitted).

In the human genome, there are 33 functional genes encoding TGF $\beta$ family polypeptides [40]. Besides the 

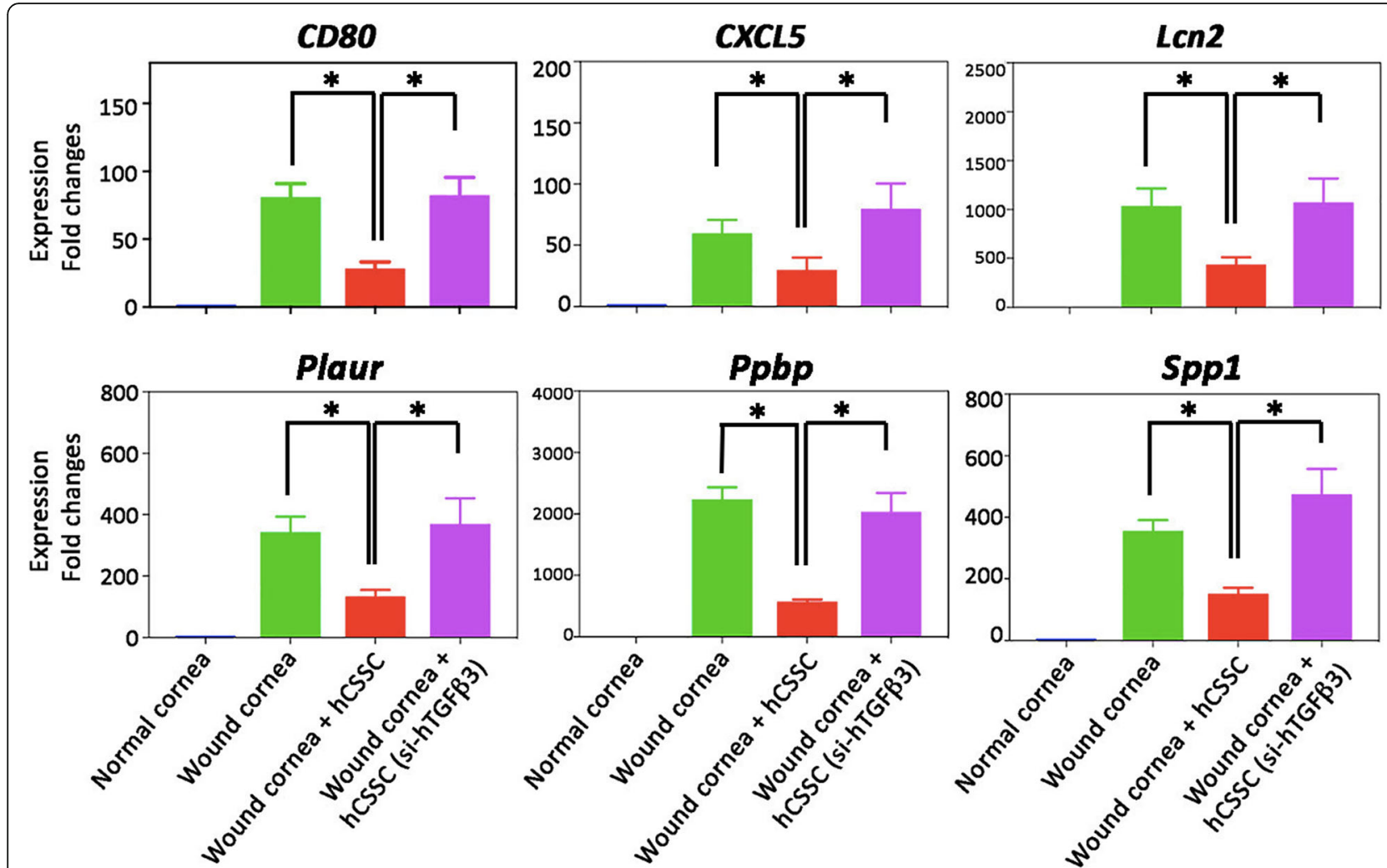

Fig. 6 The anti-inflammatory effect of hCSSC on mouse stromal wound model was attenuated by TGF 33 knockdown. After cell treatment for 1 day, mouse specific early inflammatory genes (CD80, CXCL5, LCn2, PLAUR, Ppbp and Spp 1) were upregulated in the wounded corneas, as compared to naïve corneas. Gene expression was suppressed by hCSSC treatment, representing an anti-inflammatory effect. Such a response was attenuated when hCSSC-TGF $\beta 3\left(\right.$ si) were applied. Mean and SD represent data from triplicate experiments. ${ }^{*} P<0.05$, paired Student's t-test

three TGF $\beta$ isoforms ( $\beta 1, \beta 2$ and $\beta 3)$, the family sequences consist of bone morphogenic proteins (BMPs), "growth and differentiation factors" (GDFs), activins, inhibins and nodal proteins [41]. The TGF $\beta$ isoforms regulate a variety of cellular processes in both development and adults through gene regulation via Smad- and non-Smad-dependent pathways [42]. In the context of Smad-dependent signaling, which is more extensively studied, the mature and dimeric TGF $\beta$ ligands signal through the binding to the cell surface receptor complexes that combine two type I and two type II receptors (TßRI and II), resulting in conformational changes at the ligand-receptor interface and receptor activation [43, 44]. Smad proteins then convey signals from the receptors into nucleus to modulate target gene expression (review in [42]). TGF $\beta$ isoforms have pleiotropic functions in controlling physiological phenomena during embryonic development, tissue differentiation and specialization, inflammation and immunity [29]. A broad action profile of TGF $\beta$ is also found on the proliferation and differentiation of MSC, production of ECM substances and the chemotaxis effect on various cell types involved in wound healing and the associated inflammatory responses [40].

Among the isoforms, TGF $\beta 1$ and $\beta 2$ is documented to promote fibrosis, fibroblast transition from keratocytes and myofibroblast differentiation, and to induce fibrosis and scar formation after wounding [45]. TGF 33 , on the other hand, is shown to be anti-fibrotic in skin, lung and kidney models [46-48]. In wounded human corneas, an increase in TGF $\beta 3$ levels relative to TGF- $\beta 1 / \beta 2$ isoforms was associated with a scar-free phenotype $[49,50]$. The presence of TGF $\beta 3$ in long-term culture of human stromal fibroblasts resulted in non-fibrotic characteristics and the deposited ECM resembled native stromal tissue. When compared to the treatment with TGF $\beta 1$ or $\beta 2$, the expression of Col3 and $\alpha$ SMA was suppressed by $\beta 3$, while Col1 synthesis was unaltered. In another study, TGF $\beta 3$ reduced the fibrotic gene expression of $\beta 1$ treated fibroblasts, indicating a possible "rescue" effect in addition to the preventive action on fibrosis development [32]. In a tendon injury model, the addition of TGF $\beta 3$ to tenocytes modulated Smad signaling by downregulating Smad3 and its phosphorylation, which suppressed the nuclear translocation of Smad4 and reduced 

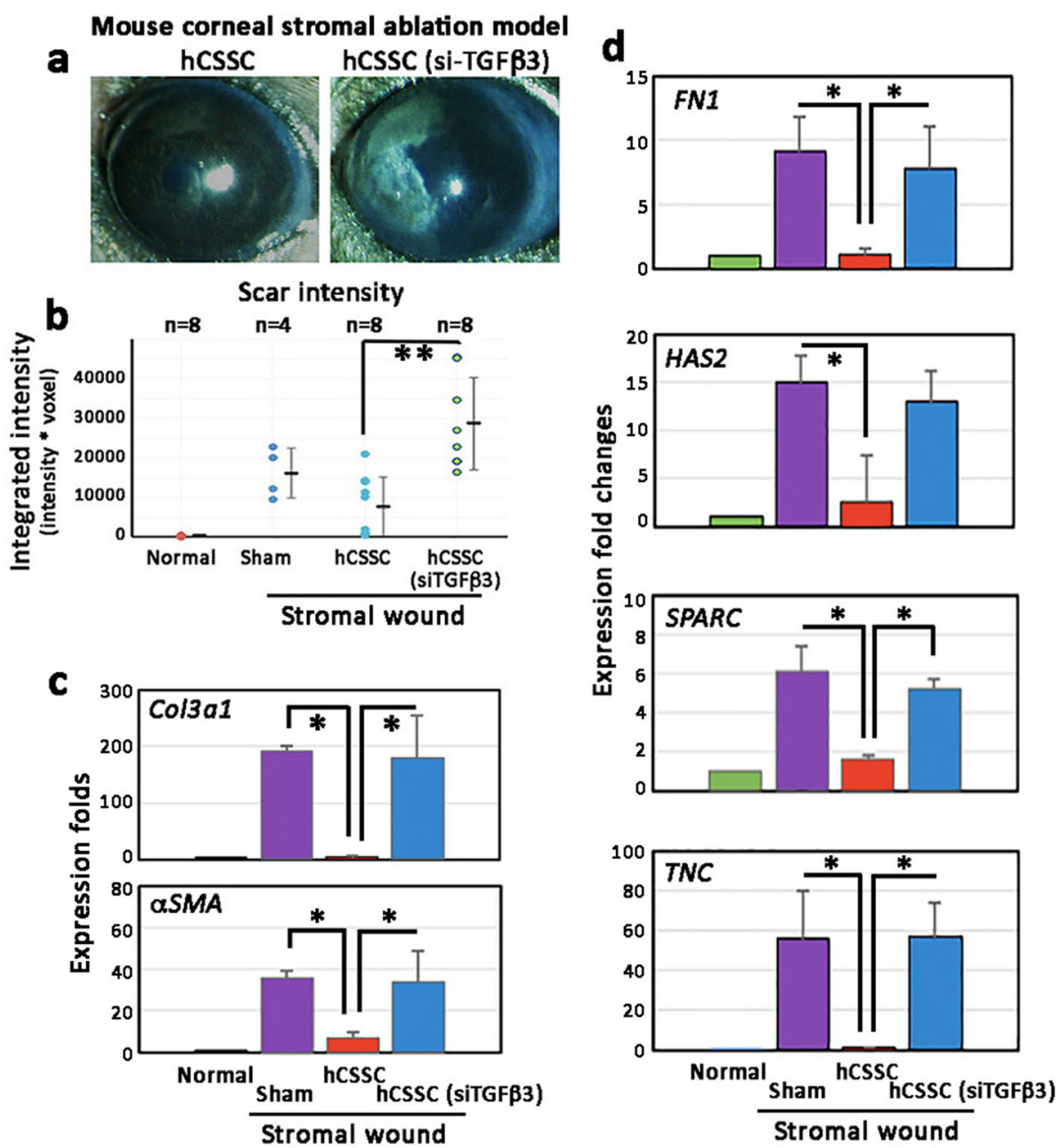

Fig. 7 The anti-fibrotic effect of hCSSC on mouse stromal wound model was reduced by TGF $\beta 3$ knockdown. Fresh wounds were treated with hCSSC or hCSSC-TGF $33($ Si). a After 14 days, intense scar was formed in corneas treated with hCSSC-TGF $33($ si), but not with naïve CSSC. b Scar intensity measurement showed that corneas treated with hCSSC-TGF 33 (si) had significantly greater scar intensities than those with naïve hCSSC. The levels were similar as in the sham control after wounding. c Mouse scar tissue genes (Col3al and aSMA) were suppressed after treatment of naive hCSSC but remained elevated for hCSSC-TGFB3(si) treatment. $\mathbf{d}$ Other mouse fibrotic genes (FN1, HAS2, SPARC and TNC) were also elevated in corneas with hCSSC-TGF 33 (si) treatment, but not with naïve hCSSC. Mean and SD are calculated from triplicate experiments. $\mathbf{b}{ }^{* *} P<0.05$, Mann-Whitney $U$ test. $\mathbf{c}, \mathbf{d}{ }^{*} P<0.05$, paired Student's t-test

fibrosis-related gene expression [51]. It also upregulated Smad7 to interact with $T \beta R 1$, which in turn prevented its phosphorylation and activation of receptor-regulated Smad2/3, and thus inhibiting TGF $\beta /$ Smad signaling.

Why TGF $\beta$ isoforms give rise to different tissue responses is still a mystery. The TGF $\beta 1, \beta 2$ and $\beta 3$ have high sequence homology and share most of their cell surface receptors. After ligand binding, the receptor phosphorylation is important in downstream activities [44]. Additional control can be exerted by ubiquitin and related molecules. T $\beta$ Rs are marked for polyubiquitination by E3 ligases, recruited via Smad7 to T $\beta R 1$ in complex, for proteasomal degradation, and hence resulting in different signaling responses $[52,53]$. Whether TGF 33 binding to $T \beta R$ complex stimulates the degradation of a particular receptor type which lead to changes in gene expression is yet to be determined. Moreover, most ligand presentations to their receptors are regulated by coreceptors, which are transmembrane proteins or proteins anchored in the membrane by glycophosphoinositol. They also mediate signaling by other cytokine receptors, giving a broad integration of signal transduction that impacts diverse cellular and pathophysiological conditions. The active TGF $\beta 1$ and $\beta 3$ peptides bind to the T $\beta R I I / I$ complex with high affinity, while $\beta 2$ engages with this receptor in the presence of co-receptor T $\beta$ RIII, a cell surface $\beta$-glycan [54]. Whether the crosstalk and differential regulation of receptor activities contribute to the different cytokine actions are important topics to be further elucidated. 


\section{Conclusion}

hCSSC deliver anti-inflammatory and anti-fibrotic effects via TGF $\beta 3$ production, supporting the role of CSSC as a therapeutic agent for corneal repair and regeneration. Without any known harmful effects, exogenous TGF $\beta 3$ can be applied to the wound site to stimulate scar-free tissue response; however, CSSC can continuously produce TGF $\beta 3$ at physiologically relevant levels. Therefore, the use of native cells is promising in the regeneration of unscarred corneal stroma to restore vision for corneal diseases.

\section{Abbreviations \\ ARG1: Arginase 1; Col3a1: Collagen 3a1; FBS: Fetal bovine serum; hCSSC: Human corneal stromal stem cells; HuNu: Human specific nuclear antigen; IL-4: Interleukin-4; iNOS: Inducible nitric oxide synthase; LPS: Lipopolysaccharides; mRAW: Mouse RAW264.7 macrophages; MSC: Mesenchymal stem cells; TGF: Transforming growth factor; TNC: Tenascin C; TNFa: Tumor necrosis factor-a; TSG-6: Tumor necrosis factor-stimulated gene 6; aSMA: a-smooth muscle actin; siRNA: Small interfering RNA}

\section{Acknowledgements}

We thank K. Davoli in histological processing of corneal samples and K Lathrop, PhD, for microscopy training.

\section{Authors' contributions}

LW, JLF: conception and design; LW, IK, MG, TY, RB, MLF: collection and assembly of data; LW, JLF, YD, GY: data analysis; JLF, YD: financial support; $L W, J L F, Y D, G Y$ : manuscript writing. All authors approved the manuscript.

\section{Funding}

This work was supported by the Department of Defence Grant W81WH-19-10778 (JLF, YD), NIH Grants RO1 EY016415 (JLF) and P30 EY008098 (JLF), Stein Innovator Award from Research to Prevent Blindness (JLF), Eye and Ear Foundation of Pittsburgh, and Louis J Fox Centre for Vision Restoration.

\section{Availability of data and materials}

Data are available from the corresponding author upon reasonable request

\section{Ethics approval and consent to participate}

This study followed the tenets set forth by the Declaration of Helsinki and was approved by the University of Pittsburgh's Institutional Review Board and Committee for Oversight of Research and Clinical Training Involving Decedents (CORID protocol \#161). The animal experiments were conducted with protocol approved by the Institutional Animal Care and Use Committee, The University of Pittsburgh (ISO00012511).

\section{Consent for publication}

Not applicable.

\section{Competing interests}

No financial and non-financial competing interest exist for any author.

\section{Author details}

${ }^{1}$ Department of Ophthalmology, University of Pittsburgh School of medicine, 203 Lothrop Street, Pittsburgh, PA 15213, USA. ² Shanghai Lanhe Optometry and Ophthalmology Clinic, Shanghai 200032, People's Republic of China.

Received: 20 May 2020 Accepted: 12 October 2020

\section{Published online: 03 November 2020}

\section{References}

1. Gain P, Julienne R, He Z, Aldossary M, Acquart S, Congnasse F, et al. Global survey of corneal transplantation and eye banking. JAMA Ophthalmol. 2016; 134(2):167-73.

2. Tan DT, Dart JK, Holland EJ, Kinoshita S. Corneal transplantation. Lancet. 2012;379(9827):1749-61.
3. Du Y, Funderburgh ML, Mann MM, Sandalraj N, Funderburgh $J$. Multipotent stem cells in human corneal stroma. Stem Cells. 2005;23(9): 1266-75.

4. Funderburgh ML, Du Y, Mann MM, SundarRaj N, Funderburgh JL. PAX6 expression identifies progenitor cells for corneal keratocytes. FASEB J. 2005; 19(10):1371-3.

5. Branch MJ, Hashmani K, Dhillon P, Jones DR, Dua HS, Hopkinson A. Mesenchymal stem cells in the human corneal limbal stroma. Invest Ophthalmol Vis Sci. 2012:53(9):5109-16.

6. Kureshi AK, Funderburgh JL, Daniels JT. Human corneal stromal stem cells exhibit survival capacity following isolation from stored organ-culture corneas. Invest Ophthalmol Vis Sci. 2014;55(11):7583-8.

7. Funderburgh JL, Funderburgh ML, Du Y. Stem cells in the limbal stroma. Ocul Surf. 2016;14(2):113-20.

8. Du Y, Sandalraj N, Funderburgh ML, Harvey SA, Birk DE, Funderburgh JL. Secretion and organization of a cornea-like tissue in vitro by stem cells from human corneal stroma. Invest Ophthalmol Vis Sci. 2007:48:5038-45.

9. Du Y, Carlson EC, Funderburgh ML, Birk DE, Pearlman E, Guo N, et al. Stem cell therapy restores transparency to defective murine corneas. Stem Cells. 2009;27(7):1635-42.

10. Basu S, Hertsenberh AJ, Funderburgh ML, Burrow MK, Mann MM, Du Y, et al. Human limbal biopsy-derived stromal stem cells prevent corneal scarring. Sci Transl Med. 2014;6(266):266ra172

11. Ghoubay D, Bordeir M, Grieve K, Martos R, Bocheux R, Nguyen TM, et al. Corneal stromal stem cells restore transparency after $\mathrm{N}_{2}$ injury in mice. Stem Cells Transl Med. 2020:9:917-35.

12. Wu J, Du Y, Mann MM, Yang E, Funderburgh JL, Wagner WR. Bioengineering organized, multilamellar human corneal stromal tissue by growth factor supplementation on highly aligned synthetic substrates. Tissue Eng Part A. 2013;19(17-18):2063-75.

13. Wu J, Du Y, Mann MM, Funderburgh JL, Wagner WR. Corneal stromal stem cells versus corneal fibroblasts in generating structurally appropriate corneal stromal tissue. Exp Eye Res. 2014;120:71-81.

14. Lagali N. Corneal stromal regeneration: current status and future therapeutic potential. Curr Eye Res. 2020;45(3):278-90.

15. Wu J, Du Y, Walkins SC, Funderburgh $\mathrm{J}$, Wagner WR. The engineering of organized human corneal tissue through the spatial guidance of corneal stromal stem cells. Biomaterials. 2012;33(5):1343-52.

16. Ghezzi CE, Marelli B, Omenetto FG, Funderburgh JL, Kapian DL. 3D functional corneal stromal tissue equivalent based on corneal stromal stem cells and multi-layered silk film architecture. PLoS One. 2017;12(1):e0169504.

17. Syed-Picard FN, Du Y, Hertsenberg AJ, Palchesko R, Funderburgh ML, Feinberg AW, et al. Scaffold-free tissue engineering of functional corneal stromal tissue. J Tissue Eng Regen Med. 2018;12(1):59-69.

18. Hertsenberg AJ, Shojaati G, Funderburgh ML, Mann MM, Du Y, Funderburgh J. Corneal stromal stem cells reduce corneal scarring by mediating neutrophil infiltration after wounding. PLoS One. 2017;12(3):e0171712.

19. Shojaati G, Khandakar I, Funderburgh ML, Mann MM, Basu R, Stolz DB, et al. Mesenchymal stem cells reduce corneal fibrosis and inflammation via extracellular vesicle-mediated delivery of miRNA. Stem Cells Transl Med. 2019:8(11):1192-201.

20. Behm B, Babilas P, Landthaler M, Schremi S. Cytokines, chemokines and growth factors in wound healing. J Eur Acad Dermatol Venereol. 2012;26(7): 812-20.

21. Doersch KM, DelloStritto DJ, Newell-Rogers MK. The contribution of interleukin-2 to effective wound healing. Exp Biol Med (Maywood). 2017; 242(4):384-96.

22. Yamakawa S, Hayashida K. Advances in surgical applications of growth factors for wound healing. Burns Trauma. 2019;7:10.

23. Karamichos D, Guo ZQ, Hutcheon AE, Zieske JD. Human corneal fibrosis: an in vitro model. Invest Ophthalmol Vis Sci. 2010;51(3):1382-8.

24. Meng XM, Nikolic-Paterson DJ, Lan HY. TGF-beta: the master regulator of fibrosis. Nat Rev Nephrol. 2016;12(6):325-38

25. Walton $\mathrm{KL}$, Johnson $\mathrm{KE}$, Harrison CA. Targeting TGF-beta mediated SMAD signaling for the prevention of fibrosis. Front Pharmacol. 2017:8:461.

26. Ling $H$, Roux E, Hempel D, Tao J, Smith M, Lonning S, et al. Transforming growth factor- $\beta$ neutralization ameliorates pre-existing hepatic fibrosis and reduces cholangiocarcinoma in thioacetamide-treated rats. PLoS One. 2013; 8(1):e54499.

27. Wang YW, Liou NH, Cherng JH, Chang SJ, Ma KH, Fu E, et al. siRNAtargeting transforming growth factor-beta I receptor reduces wound 
scarring and extracellular matrix deposition of scar tissue. J Invest Dermatol. 2014;134(7):2016-25.

28. Yoshizawa H, Morishita $Y$, Watanabe M, Ishibashi K, Muto S, Kusano E, et al. TGF- $\beta_{1}$-siRNA delivery with nanoparticles inhibits peritoneal fibrosis. Gene Ther. 2015;22(4):333-40.

29. Wojdasiewicz P, Poniatowski LA, Szukiewicz D. The role of inflammatory and anti-inflammatory cytokines in the pathogenesis of osteoarthritis. Mediat Inflamm. 2014;2014:561459.

30. Saika S, Yamanaka O, Okada Y, Tanaka S, Miyamoto T, Sumioka T, et al. TGF$\beta$ in fibroproliferative diseases in the eye. Front Biosci (Schol Ed). 2009;1: 376-90.

31. Gilbert RWD, Vickaryous MK, Viloria-Petit AM. Signalling by transforming growth factor $\beta$ isoforms in wound healing and tissue regeneration. J Dev Biol. 2016;4(2):21.

32. Karamichos $D$, Hutcheon $A E$, Zieske JD. Transforming growth factor $\beta 3$ regulates assembly of a non-fibrotic matrix in a $3 \mathrm{D}$ corneal model. J Tissue Eng Regen Med. 2011;5(8):e228-38.

33. Ferguson MW, O'Kane S. Scar-free healing: from embryonic mechanisms to adult therapeutic intervention. Philos Trans R Soc Lond Ser B Biol Sci. 2004; 359(1445):839-50.

34. Jiang Y, Vaessen B, Lenvik T, Blackstad M, Reyes M, Verfaillie CM. Multipotent progenitor cells can be isolated from postnatal murine bone marrow, muscle, and brain. Exp Hematol. 2002;30(8):896-904.

35. Bardi GT, Smith MA, Hood JL. Melanoma exosomes promote mixed $M_{1}$ and $\mathrm{M}_{2}$ macrophage polarization. Cytokine. 2018;105:63-72.

36. Taciak B, Bialasek M, Braniewska A, Sas Z, Sawicka P, Kiraga L, et al. Evaluation of phenotypic and functional stability of RAW 264.7 cell line through serial passages. PLoS One. 2018;13(6):e0198943.

37. Madej MP, Topfer E, Boraschi D, Italiani P. Different regulation of interleukin1 production and activity in monocytes and macrophages: innate memory as an endogenous mechanism of IL-1 inhibition. Front Pharmacol. 2017;8: 335.

38. Gubernatorova EO, Gorshikova EA, Namakanova OA, Zvartsev RV, Hidalgo J, Drutskaya MS, et al. Non-redundant functions of IL-6 produced by macrophages and dendritic cells in allergic airway inflammation. Front Immunol. 2018:9:2718.

39. Prockop DJ, Oh JY. Mesenchymal stem/stromal cells (MSCs): role as guardians of inflammation. Mol Ther. 2012;20(1):14-20.

40. Morikawa M, Derynck R, Miyazono K. TGF- $\beta$ and the TGF- $\beta$ family: contextdependent roles in cell and tissue physiology. Cold Spring Harb Perspect Biol. 2016;8(5):a021873.

41. Wakefield LM, Hill CS. Beyond TGF $\beta$ : roles of other TGF- $\beta$ superfamily members in cancer. Nat Rev Cancer. 2013;13(5):328-41.

42. Derynck R, Budi EH. Specificity, versatility, and control of TGF- $\beta$ family signaling. Sci Signal. 2019;12(570):eaav5183.

43. Cheifetz S, Wathebee JA, Tsang ML, Anderson JK, Mole JE, Lucas R, et al. The transforming growth factor $\beta$ system, a complex pattern of cross-reactive ligands and receptors. Cell. 1987;48(3):409-15.

44. Chaikuad A, Bullock AN. Structural basis of intracellular TGF- $\beta$ signaling: receptors and smads. Cold Spring Harb Perspect Biol. 2016;8(11):a022111.

45. Biernacka A, Dobaczewski M, Frangogiannis NG. TGF- $\beta$ signaling in fibrosis. Growth Factors. 2011;29(5):196-202.

46. Yu L, Border WA, Huang Y, Noble NA. TGF- $\beta$ isoforms in renal fibrogenesis. Kidney Int. 2003;64(3):844-56.

47. Ask K, Bonnaiaud P, Maass K, Eickelberg O, Margetts PJ, Warburton D, et al. Progressive pulmonary fibrosis is mediated by TGF- $\beta 1$ but not TGF- $\beta 3$. Int J Biochem Cell Biol. 2008;40(3):484-95.

48. Han A, Bandyopadhyay B, Jayapraksah P, Lua I, Sahu D, Chen M, et al. The anti-motility signaling mechanism of TGF $\beta 3$ that controls cell traffic during skin wound healing. Biol Open. 2012;1 (12):1169-77.

49. Guo X, Hutcheon AE, Zieske JD. Molecular insights on the effect of TGF- $\beta 1 /$ $-\beta 3$ in human corneal fibroblasts. Exp Eye Res. 2016;146:233-41.

50. Karamichos $D$, Hutcheon AE, Zieske JD. Reversal of fibrosis by TGF- $\beta 3$ in a 3D in vitro model. Exp Eye Res. 2014;124:31-6.

51. Jiang K, Chun G, Wang Z, Du Q, Wang A, Xiong Y. Effect of transforming growth factor- $\beta 3$ on the expression of Smad3 and Smad7 in tenocytes. Mol Med Rep. 2016;13(4):3567-73.

52. Kavsak P, Rasmussen RK, Causign CG, Bonni S, Zhu H, Thomsen GH. Smad7 binds to Smurf2 to form an E3 ubiquitin ligase that targets the TGF $\beta$ receptor for degradation. Mol Cell. 2000;6(6):1365-75.
53. Ebisawa T, Fukuchi M, Murakami G, Chiba T, Tanaka K, Imamura T, et al. Smurf1 interacts with transforming growth factor- $\beta$ type I receptor through Smad7 and induces receptor degradation. J Biol Chem. 2001;276(16):1247780.

54. Heldin $\mathrm{CH}$, Moustakas A. Signaling receptors for TGF- $\beta$ family members. Cold Spring Harb Perspect Biol. 2016:8(8):a022053.
Ready to submit your research? Choose BMC and benefit from:

- fast, convenient online submission

- thorough peer review by experienced researchers in your field

- rapid publication on acceptance

- support for research data, including large and complex data types

- gold Open Access which fosters wider collaboration and increased citations

- maximum visibility for your research: over $100 \mathrm{M}$ website views per year

At BMC, research is always in progress.

Learn more biomedcentral.com/submissions 